\title{
Editorial
}

\section{Storm Tide and Wave Simulations and Assessment II}

\author{
Shih-Chun Hsiao ${ }^{1} \mathbb{D}$, Wen-Son Chiang ${ }^{2}$ and Wei-Bo Chen ${ }^{3, * \mathbb{D}}$ \\ 1 Department of Hydraulic and Ocean Engineering, National Cheng Kung University, Tainan 701, Taiwan; \\ schsiao@mail.ncku.edu.tw \\ 2 Tainan Hydraulics Laboratory, National Cheng Kung University, Tainan 70101, Taiwan; \\ chws@mail.ncku.edu.tw \\ 3 National Science and Technology Center for Disaster Reduction, New Taipei 231, Taiwan \\ * Correspondence: wbchen@ncdr.nat.gov.tw; Tel.: +886-2-8195-8611
}

\section{check for}

updates

Citation: Hsiao, S.-C.; Chiang, W.-S.; Chen, W.-B. Storm Tide and Wave Simulations and Assessment II. J. Mar. Sci. Eng. 2022, 10, 379. https:// doi.org/10.3390/jmse10030379

Received: 24 February 2022

Accepted: 1 March 2022

Published: 6 March 2022

Publisher's Note: MDPI stays neutral with regard to jurisdictional claims in published maps and institutional affiliations.

Copyright: (C) 2022 by the authors. Licensee MDPI, Basel, Switzerland. This article is an open access article distributed under the terms and conditions of the Creative Commons Attribution (CC BY) license (https:// creativecommons.org/licenses/by/ $4.0 /)$.

\section{Introduction}

The storm tides, surges, and waves that are associated with typhoons/tropical cyclones/hurricanes are the most severe threats to coastal zones, nearshore waters, and navigational safety. Therefore, predicting typhoon/tropical cyclone/hurricane-induced storm tides, surges, waves, and coastal erosion is essential for reducing the loss of human life and property as well as for mitigating coastal disasters. There is still a growing demand for novel techniques that could be adopted to resolve the complex physical processes of storm tides, surges, waves, and coastal erosion, even if many studies on the hindcasting/predicting/forecasting of typhoon-driven storm tides, surges, and waves as well as on morphology evolution have been carried out through the use of numerical models in the last decade.

The intention of this Special Issue was to collect the latest studies on storm tide, surge, and wave modeling and analysis utilizing dynamic and statistical models and artificial intelligence approaches to improve our simulation and analytic capabilities and our understanding of storm tides, surges, and waves. Five high-quality papers were accepted for publication in this Special Issue; these papers cover the application and development of many high-end techniques that can be used to study storm tides, surges, waves as well as for on-site investigations of coastal erosion and accretion.

\section{Details of Papers}

To analyze wave-induced effects on sea surface temperature simulations during typhoon events, Sun et al. [1] investigated sea surface temperature (SST) cooling under binary typhoon conditions. They mainly focused on parallel- and cross-type typhoon paths during four typhoon events: Tembin and Bolaven in 2012 and Typhoon Chan-hom and Linfa in 2015. Wave-induced effects were simulated using a third-generation numeric model, WAVEWATCH III (WW3), and were subsequently included in SST simulations using the Stony Brook Parallel Ocean Model (sbPOM). They indicated that the vertical profile of the SST simulation indicated that the disturbance depth increased (up to $100 \mathrm{~m}$ ) for cross-type typhoon paths because the mixing intensity was greater for the cross-type typhoons than it was for the parallel-type typhoons.

To assess the effects of depth-induced breaking on wind wave simulations in the shallow nearshore waters off of northern Taiwan during the passage of two super typhoons using a high-resolution coupled wave-circulation model, Hsiao et al. [2] found that the significant wave height that was induced by the typhoon winds in the surf zone were more sensitive to the different wave-breaking formulations that were used in the wave-circulation model. The significant wave height simulations in the surf zone were insensitive to the wave-breaking criterion $(\gamma)$ during the passage of typhoons. In shallow nearshore waters, the utilization of a constant $\gamma$ for the wave-circulation model always 
produced peak significant wave heights that are smaller than those that were achieved when $\gamma$ based on local steepness or peak steepness was used.

To evaluate the focusing waves induced by Bragg resonance with a V-shaped undulating bottom, Zhang et al. [3] proposed sinusoidal sandbars with a horizontal V-shaped pattern that was formed by two continuous undulating bottoms that were inclined towards each other at an angle with the center axis perpendicular to the shoreline. Based on the high-order spectral (HOS) numerical model, both the Bragg resonance characteristics that were induced by the regular waves and random waves were investigated. With regular waves, the study showed that the wave-focusing effect is related to the angle of the V-shaped undulating bottom and that the optimal angle of inclination for the V-shaped undulating bottom is $162.24^{\circ}$

To derive the 100-year total water level around the coast of Corsica by combining trivariate extreme value analysis and coastal hydrodynamic models, Louisor et al. [4] focused on providing extreme scenarios through which wind wave and coastal hydrodynamic models, i.e., SWAN and SWASH-2DH, could be populated in order to compute the 100 -year total water level (100y-TWL) along the coasts. They showed how the proposed multivariate extreme value analysis can help to more accurately define low-lying zones that are potentially exposed to coastal flooding, especially in Corsica, where a unique value of $2 \mathrm{~m}$ was taken into account in previous studies. The computed 100y-TWL values were determined to be between $1 \mathrm{~m}$ along the eastern coasts and $1.8 \mathrm{~m}$ on the western coast. The calculated values are also below the $2.4 \mathrm{~m}$ threshold that is recommended when considering sea level rise (SLR). Their results highlight the added value of performing a complete integration of extreme offshore conditions together with their dependence on hydrodynamic simulations for screening out the coastal areas that may potentially be exposed to flooding.

For the on-site investigation of coastal erosion and accretion for the northeast region of Taiwan, Liang et al. [5] investigated coastal erosion and accretion in that area through a series of on-site surveys. The results of the bathymetric surveys suggest that the shoreline of Yilan County tends to accrete during the summer because of abundant sediment from the rivers; however, the shoreline is eroded in winter due to the large waves that are induced by the northeast monsoon. Additionally, the calculated net volume of erosion and accretion between each pair of cross sections showed that the length of the coastline that impacted by estuarine sediment transport is approximately $2 \mathrm{~km}$ long and spans from north to south along the Lanyang River estuary coastline.

Funding: This research received no external funding.

Conflicts of Interest: The authors declare no conflict of interest.

\section{References}

1. Sun, Z.; Shao, W.; Yu, W.; Li, J. A Study of Wave-Induced Effects on Sea Surface Temperature Simulations during Typhoon Events. J. Mar. Sci. Eng. 2021, 9, 622. [CrossRef]

2. Hsiao, S.-C.; Wu, H.-L.; Chen, W.-B.; Guo, W.-D.; Chang, C.-H.; Su, W.-R. Effect of Depth-Induced Breaking on Wind Wave Simulations in Shallow Nearshore Waters off Northern Taiwan during the Passage of Two Super Typhoons. J. Mar. Sci. Eng. 2021, 9, 706. [CrossRef]

3. Zhang, H.; Tao, A.; Tu, J.; Su, J.; Xie, S. The Focusing Waves Induced by Bragg Resonance with V-Shaped Undulating Bottom. J. Mar. Sci. Eng. 2021, 9, 708. [CrossRef]

4. Louisor, J.; Rohmer, J.; Bulteau, T.; Boulahya, F.; Pedreros, R.; Maspataud, A.; Mugica, J. Deriving the 100-Year Total Water Level around the Coast of Corsica by Combining Trivariate Extreme Value Analysis and Coastal Hydrodynamic Models. J. Mar. Sci. Eng. 2021, 9, 1347. [CrossRef]

5. $\quad$ Liang, T.-Y.; Chang, C.-H.; Hsiao, S.-C.; Huang, W.-P.; Chang, T.-Y.; Guo, W.-D.; Liu, C.-H.; Ho, J.-Y.; Chen, W.-B. On-Site Investigations of Coastal Erosion and Accretion for the Northeast of Taiwan. J. Mar. Sci. Eng. 2022, 10, 282. [CrossRef] 